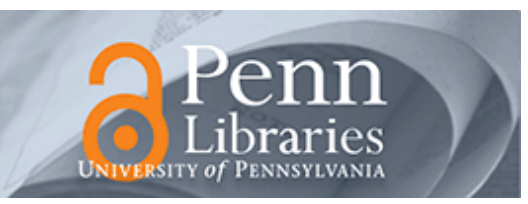

University of Pennsylvania

ScholarlyCommons

Departmental Papers (CBE)

Department of Chemical \& Biomolecular

Engineering

August 2006

\title{
Efficient Nuclear Delivery and Nuclear Body Localization of Antisense Oligo-Nucleotides using Degradable Polymersomes
}

\author{
Younghoon Kim \\ University of Pennsylvania \\ Manu Tewari \\ University of Pennsylvania \\ J. David Pajerowski \\ University of Pennsylvania \\ Shamik Sen \\ University of Pennsylvania \\ Williams Jason \\ Drexel University \\ Follow this and additional works at: https://repository.upenn.edu/cbe_papers
}

See next page for additional authors

Recommended Citation

Kim, Y., Tewari, M., Pajerowski, J. D., Sen, S., Jason, W., Sirsi, S., Lutz, G., \& Discher, D. E. (2006). Efficient

Nuclear Delivery and Nuclear Body Localization of Antisense Oligo-Nucleotides using Degradable

Polymersomes. Retrieved from https://repository.upenn.edu/cbe_papers/112

Copyright 2006 IEEE. Reprinted from Proceedings of the 28th IEEE EMBS Annual International Conference, August 2006, pages 4350-4353.

This material is posted here with permission of the IEEE. Such permission of the IEEE does not in any way imply IEEE endorsement of any of the University of Pennsylvania's products or services. Internal or personal use of this material is permitted. However, permission to reprint/republish this material for advertising or promotional purposes or for creating new collective works for resale or redistribution must be obtained from the IEEE by writing to pubs-permissions@ieee.org. By choosing to view this document, you agree to all provisions of the copyright laws protecting it.

This paper is posted at ScholarlyCommons. https://repository.upenn.edu/cbe_papers/112

For more information, please contact repository@pobox.upenn.edu. 


\title{
Efficient Nuclear Delivery and Nuclear Body Localization of Antisense Oligo- Nucleotides using Degradable Polymersomes
}

\begin{abstract}
Delivery of antisense oligonucleotides, AON, presents many of the same challenges as delivery of any nucleic acid: charge, stability, cell uptake, endolysosomal escape, and entry into the nucleus. Here we demonstrate efficient delivery of AON after loading into biodegradable polymer vesicles or 'polymersomes'. We focus on AON delivery to muscle cells in vitro and in vivo because of the emergence of AON in therapeutic strategies directed at muscular dystrophies. To first clarify uptake kinetics without the complications of typical multi-layered myotube cultures, we use micro-patterned $\mathrm{C} 2 \mathrm{C} 12$ cells and show efficient uptake of AON-polymersomes. The biodegradable polymersomes break down and foster AON escape with the binding of fluorescent-AON into the nuclear bodies. Intramuscular injections of the polymersome-AON into the hind limbs of $m d x$-dystrophic mice show more efficient nuclear uptake than AON alone and also lead to dystrophin expression in the mdx mice. In sum, these neutral, degradable carriers of AON show promise in vivo.
\end{abstract}

\section{Comments}

Copyright 2006 IEEE. Reprinted from Proceedings of the 28th IEEE EMBS Annual International Conference, August 2006, pages 4350-4353.

This material is posted here with permission of the IEEE. Such permission of the IEEE does not in any way imply IEEE endorsement of any of the University of Pennsylvania's products or services. Internal or personal use of this material is permitted. However, permission to reprint/republish this material for advertising or promotional purposes or for creating new collective works for resale or redistribution must be obtained from the IEEE by writing to pubs-permissions@ieee.org. By choosing to view this document, you agree to all provisions of the copyright laws protecting it.

\section{Author(s)}

Younghoon Kim, Manu Tewari, J. David Pajerowski, Shamik Sen, Williams Jason, Shashank Sirsi, Gordon Lutz, and Dennis E. Discher 


\title{
Efficient Nuclear Delivery and Nuclear Body Localization of Antisense Oligo-Nucleotides using Degradable Polymersomes
}

\author{
Younghoon $\mathrm{Kim}^{1}{ }^{*}$, Manu Tewari ${ }^{1}$, David J. Pajeroski ${ }^{1}$, Shamik Sen ${ }^{1}$, \\ Williams Jason ${ }^{2}$, Shashank Sirsi ${ }^{2}$, Gordon Lutz ${ }^{2}$ and Dennis E. Discher ${ }^{1}$
}

\begin{abstract}
Delivery of antisense oligonucleotides, AON, presents many of the same challenges as delivery of any nucleic acid: charge, stability, cell uptake, endolysosomal escape, and entry into the nucleus. Here we demonstrate efficient delivery of AON after loading into biodegradable polymer vesicles or 'polymersomes'. We focus on AON delivery to muscle cells in vitro and in vivo because of the emergence of $\mathrm{AON}$ in therapeutic strategies directed at muscular dystrophies. To first clarify uptake kinetics without the complications of typical multi-layered myotube cultures, we use micro-patterned $\mathrm{C} 2 \mathrm{C} 12$ cells and show efficient uptake of AON-polymersomes. The biodegradable polymersomes break down and foster AON escape with the binding of fluorescent-AON into the nuclear bodies. Intramuscular injections of the polymersome-AON into the hind limbs of $m d x$-dystrophic mice show more efficient nuclear uptake than AON alone and also lead to dystrophin expression in the mdx mice. In sum, these neutral, degradable carriers of AON show promise in vivo.
\end{abstract}

\section{INTRODUCTION}

Synthetic vesicles by polyethylene oxide-polybutadiene (PEO-PBD) or polyethylene oxide-polycaprolactone (PEO-PCL) have advantages 1) carriers are so inert that it does not cause inflammation 2) they are so stealthy that they can circulate in vivo for long time, compared to cationic carriers and lipid vesicles [1-5]. Programmable release of encapsulants by controlling the ratio of PEO-PBD/PEO-polyesters would be another advantage [6, 7]. Recently, endosomal release mechanism was elucidated by computer simulation by F.Ahmed [8].

Antisense oligonucleotides (AON) are being increasingly used to work around deleterious mutations and/or deletions, including the dystrophin gene that leads to muscular dystrophy. The significant advantage of AONs is the ability to target the gene irrespective of its large size and clinical applicability as small-molecule based therapy [9]. However, efficient delivery of AONs in muscles is a great challenge and much depends on the carriers that provide protection against degradation, cell specificity and release [10-12].

This work was supported in part by the NIH, NSF, NTI, and MRSEC.

1. Department of Chemical \& Biomolecular Engineering and Pennsylvania Muscle Institute, University of Pennsylvania, 19104 PA Philadelphia USA, *equal contributors

2. Department of Pharmacology, College of Medicine, Drexel University, Philadelphia, USA

Correspondence: discher@seas.upenn.edu, phone: +1-215-898-9950, fax: $+1-215-573-2093$
Here we detail the AON delivery by controlled-release polymersomes. AON was encapsulated within PBO-PBD/PEO-PCL blend vesicles for programmable release. The AON delivery into muscle cells for corrective therapy depends much upon the delivery system that provides advantages of site-specific delivery, protection from nucleases and tailored release. PEGylated micelles or polymersomes have nontoxic, inert properties and cells can take them up to be transported perinucleus region without any further modification [13]. 6-fem (green) labeled AON and TMRCA-labeled (red) copolymer altogether helped to visualize the process of endocytosis to $\mathrm{C} 2 \mathrm{C} 12$ muscle cells and the nucleus localization of gene.

\section{RESULTS}

\section{A. Loading of AON in polymer vesicles "polymersome"}

Degradable, self-porating polymer vesicles, polymersomes, were made with non-degradable and degradable copolymers. Upon the composition of polymer membrane, the releasing kinetics from vesicles could be programmed. Our group described this finding in the prior report [14]. Briefly, polyethylene oxide-poly butadiene makes inert, stable bilayer vesicle structures. The PEG-PBD vesicles are extremely stabilized and do not break over time [15]. This property was used for encapsulating small molecules like drug or dyes.

To release their encapsulants, hydrolysable polyethylene oxide - poly lactic acid or polyethylene oxide - poly caprolactic acid was mixed to make bilayer polymer vesicles [14]. Blended polymer vesicles were good for encapsulating small molecular weight drugs and used for anti-cancer therapy [8]. In this study, antisense oligonucleotide could be loaded within polymer vesicles and released over the programmed time as in Fig. 1.

The releasing kinetics of polymersomes, which were

TABLE I

PHYSICAL PROPERTIES OF VARIOUS DIBLOCK COPOLYMERS

\begin{tabular}{ccccc}
\hline \hline $\begin{array}{c}\text { Copolymer } \\
\text { name }\end{array}$ & $\begin{array}{c}\text { FORMULA } \\
\mathrm{A}_{\mathrm{M}}-\mathrm{B}_{\mathrm{N}}\end{array}$ & $\begin{array}{c}\mathrm{Mn} \\
(\mathrm{kg} / \mathrm{mol})\end{array}$ & P.D. & $w_{E O}$ \\
\hline OB2 & $\mathrm{EO}_{26}-\mathrm{BD}_{46}$ & 3.6 & 1.09 & 0.33 \\
OCL4 & $\mathrm{EO}_{52}-\mathrm{CL}_{44}$ & 7.0 & 1.30 & 0.29 \\
\hline \hline
\end{tabular}


$\mathbf{a}$

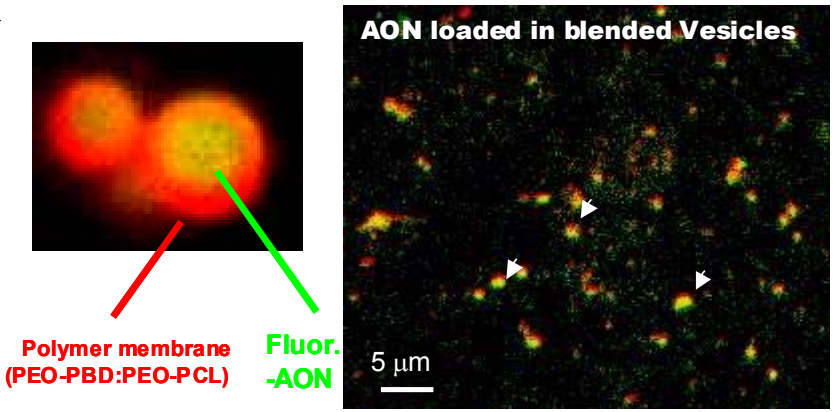

b

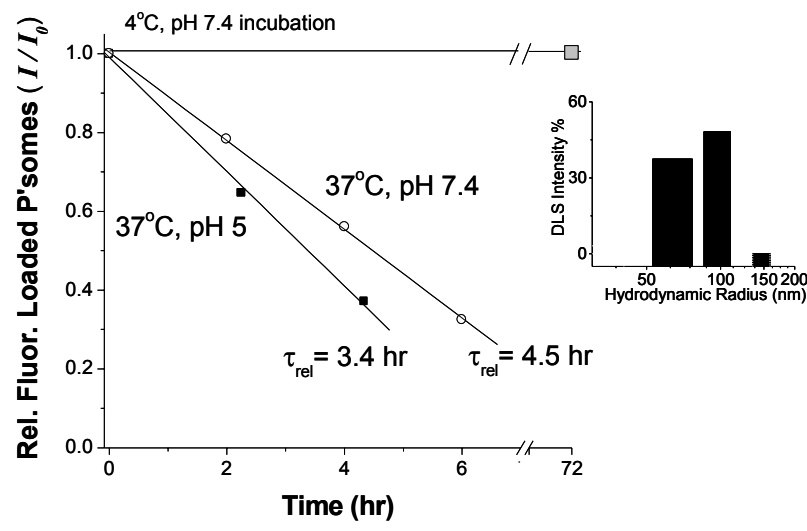

Fig. 1. Encapsulation and release of AON from polymersomes.

(a) Bio-degradable AON (green) loaded vesicles, formed in DMSO-PBS (15:85) using blended polymers PEO-PBD \& PEO-PCL $(1: 3 \mathrm{w} / \mathrm{w}$, red). (b) Self-porating vesicles with PEO-PBD \& PEO-PCL (1:3) show sustained release of encapsulants, depending on temperature and $\mathrm{pH}$. Under slightly acidic conditions typical of endolysosomes, release is accelerated. At $4{ }^{\circ} \mathrm{C}$, leakage over days is undetectable. Inset: Polymersomes sized down to $100 \mathrm{~nm}$ radiuses by sonication and extrusion and measured by dynamic light scattering (DLS).

composed of 1:3 ratio of PEO-PBD and PEO-PCL were tuned for cell culture and animal studies. The releasing profiles of self-porating vesicles were examined at two conditions. For physiological conditions at $37 \mathrm{C}, \mathrm{pH} 7.4,290$ mOsm, for acidic intercellular condition, at $\mathrm{pH} 5.5$ were measured. The hydrolysis of PEO-PCL was accelerated in acidic condition, so the releasing time was shortened in the acidic condition [16]; half time for releasing was $4.5 \mathrm{hrs}$ at $\mathrm{pH} 7.4$ and $3.4 \mathrm{hrs}$ at $\mathrm{pH}$ 5.5. The vesicles were stable at $4 \mathrm{C}$ for 3 days with no significant release of AON. At low temperature, hydrolysis is extremely suppressed and rupturing of vesicle membrane progressed very slowly [17].

\section{B. Uptake of non-degradable " polymersomes" by C2C12 myotubes}

Polymersomes can enter cells without targeting moieties because they have neutral $\mathrm{pH}$ and has poly ethylene glycol brushes on them. With long polyethylene oxide brushes on their surface, polymersomes have minimal cyto-toxicities and long circulation time in vivo [5]. F.Ahmed elucidated the cyto-toxicity and uptake mechanism of polymersomes [8].

To see the uptake by cells, especially muscle cells, well-defined muscle cell strips were used. On one separated muscle cell strips, the interaction of polymersome and cells could be observed easily, than in the interconnected and congested multi-nucleated myotubes. The well-defined patterns made it possible to distinguish between the polymersomes uptake of and non-specific binding to the glass surface. $\mathrm{C} 2 \mathrm{C} 12$ myotubes grown on well-defined collagen coated IPN-patterns were used to study the cellular uptake and kinetics of non-degradable polymer, PEO-PBD. TMRCA conjugated polymers were mixed in polymersomes $(1 \mathrm{mg} / \mathrm{ml}$ initial concentration) to be added to the $\mathrm{C} 2 \mathrm{C} 12$ myotubes, and muscle cell patterns showed efficient uptake of polymeric vesicles in $1 \mathrm{hr}$. The inert PEO-PBD vesicles showed punctated perinuclear localization within the myotube. Initially, punctuate distributions of internalized vesicles appeared throughout the cells with gradual accumulation in the perinuclear regions.
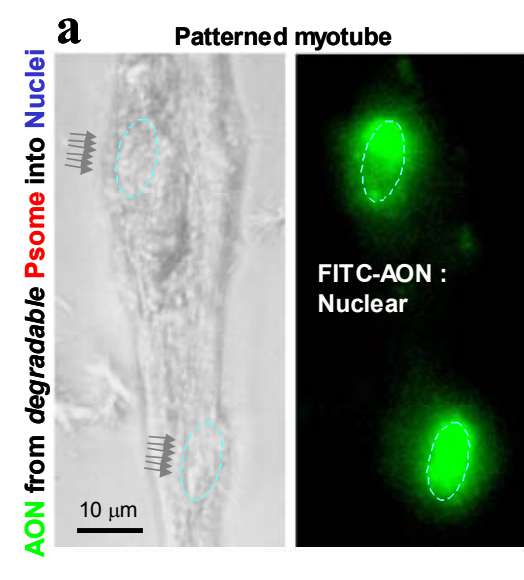

b Myotubes in petri-dish
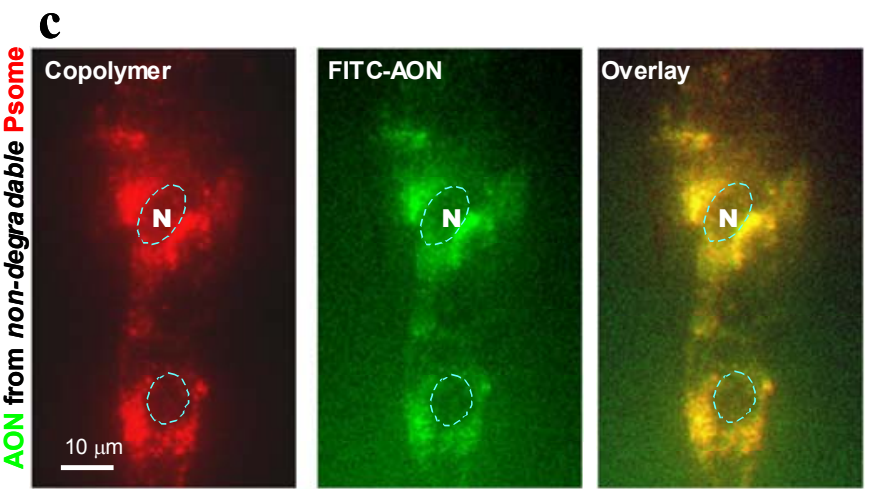

Fig. 2. In vitro delivery of antisense oligonucleotide using biodegradable polymer vesicles.

(a) Bright field image showing a single patterned myotube after delivery with no signs of apoptosis (left). Fluorescent image of delivered AON in nuclei of the top-layer of the myotube (right). Scale bar is 10 microns (b) Delivery of AON in nuclei of myotubes grown in petri dish. Overlay shows the AON transfected nuclei and blue (Hoechst dye) the total nuclei. (c) Delivery of non-degradable PEO-PBD vesicles. Patterned myotubes show punctated perinuclear delivery of AON-loaded Polymer 

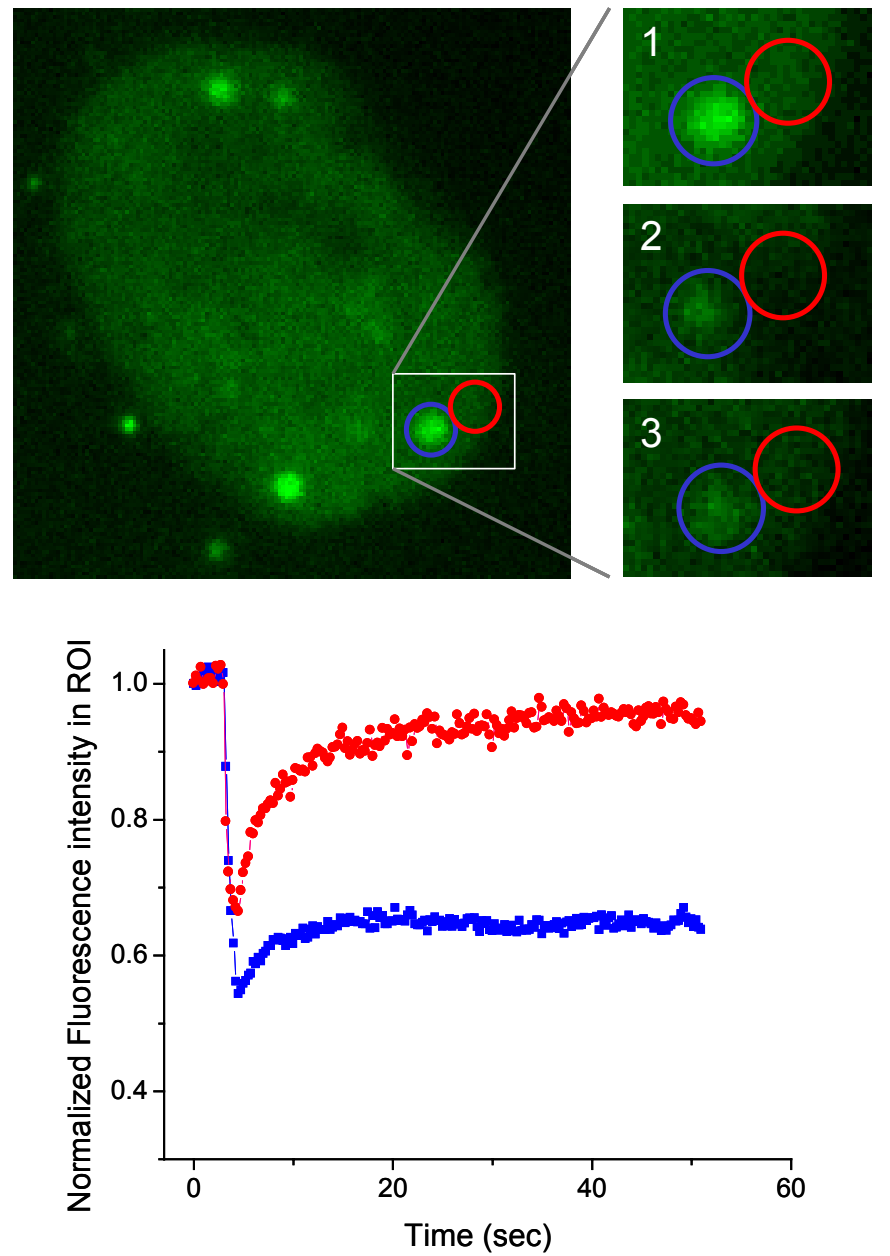

Fig. 3. Intranuclear delivery of fluorescent-AON.

Magnified views of muscle nuclei showed a few discrete spots that are likely concentrations at nuclear bodies. FRAP was conducted both on and off of the spots. The latter (red) showed quick and complete recovery of fluorescence indicating high mobility, whereas the nuclear bodies (blue) showed little recovery.

\section{In vitro Release and delivery of $A O N$ into $C 2 C 12$ myotubes}

Using degradable polymersome, encapsulated antisense could be delivered to nuclei. Polymersomes delivered antisense into cells and after certain time, polymer-shells were hydrolyzed and encapsulated antisense was released. The endolysomal delivery mechanism was suggested by Fariyal Ahmed using MC simulation [8].

In the patterned IPN muscle cell strips, antisense were delivered into both of top layers and bottom layers. In figure 2.a, the nucleus at upper part is nucleus located at the top layer and other nucleus is located at the bottom layer. Congested muscle cells in petri dish were also tested for delivery. The delivery was fairly comparable to PEI coupled antisense oligonucleotide. The transfection efficiency of polymer-loaded AON was comparable to PEI complexed AON, which was used as control. Free AON did not show

any significant nuclear delivery in myotubes grown in culture.

\section{Sub-cellular distribution of AON in nucleus}

After uptake of polymersomes by cells, polymersomes were located near nucleus and antisense was released and delivered to nucleus. In nucleus localization stage, antisense behavior was observed with pulse laser, which will exhaust the antisense fluorescence. High magnification images showed that antisense were stuck to some peculiar spots, and looked like antisense was not moving around any more. To confirm the mobility of antisense in nucleus, a milli-second pulse laser was shot for photo bleaching. This FRAP study gave some idea about where antisense is located at after delivery.

FRAP study found that negatively charged antisense will be bound to somewhere in nucleus and rest of them will float freely around. In Figure 3, blue circle is background and pink circle is the fixed small spot. After few milli-seconds of photo bleaching, the fluorescence of blue and pink circles were completed (figure 3.2) the fluorescence intensity went down. The fluorescence was recovered in the certain time (figure 3.3). Although the background fluorescence was recovered almost up to the previous fluorescence level, the specific spot fluorescence did not come back as much. Only around $10 \%$ intensity levels came back on the pink spot, but more than $30 \%$ intensity levels were recovered in background, blue spot.

\section{E. In-vivo delivery of AON-polymersomes in mdx-mice by intramuscular injections:}

Dystrophin-defective mdx mice, which are DMD model mice, were used for intramuscular delivery, and the

\section{a}

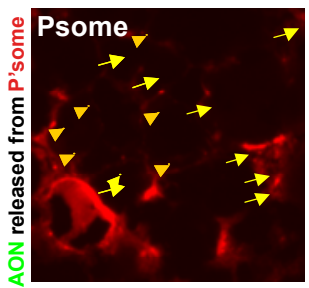

b
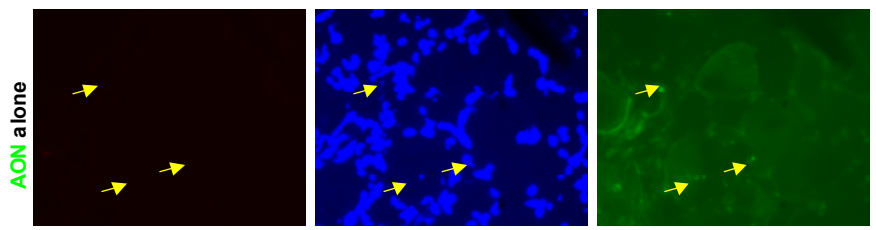

Fig. 4. Intra muscular AON delivery in $m d x$ mice.

(a) Nuclear delivery of AON after release, shown in TA-muscle sections post $12 \mathrm{hrs}$ injection. Fluorescent images show red-labeled biodegradable polymersomes (diffused), blue nuclei (total) and green AON (nuclei). (b) AON delivery in nuclei after $12 \mathrm{hrs}$ post injection of AON alone (no carrier) as control. 
efficiency of delivery was observed. In $24 \mathrm{hrs}$ of injection point, mice were sacrificed and TA muscles were pulled out to snap-freeze to see antisense delivery. The delivery efficiency was counted as the number of overlaid nuclei by green fluorescence by antisense and blue-fluorescence by nuclei. The red fluorescence in polymersomes did not bleed into green emission range.

Also the efficiency of dystrophin restoration was tested. Initial experiments were performed in $m d x$ mice 6-8 weeks (referred to as 6 weeks) of age with a single dose of 3 micro grams AON loaded in polymer vesicles. Three weeks after intramuscular injection, immunohistochemistry showed significant increases in the number of dystrophin-positive fibers in all skeletal muscles of the treated mice when compared with age-matched control $m d x$ mice. However, the number of dystrophin-positive fibers varied between different areas of individual skeletal muscles and even between neighboring fibers.

\section{ACKNOWLEDGMENT}

Authors thank prof. Paul Jamney for DLS equipments and prof. Eric Boder for his support. This work was supported by an NIH R21 from NIBIB, the NTI, and NSF-MRSEC.

\section{REFERENCES}

[1] Charles M. Roth, S. S. "ENGINEERING SYNTHETIC VECTORS FOR IMPROVED DNA DELIVERY: Insights from Intracellular Pathways," Апnu Rev Biomed Eng, vol. 6, pp. 397-426, 2004

[2] Oliver Meyer, K. D., Hong K, Sternberg B, Park JW, Woodle MC, Papahadjopoulos D., "Cationic liposomes coated with polyethylene glycol as carriers for oligonucleotides," The Journal of Biological Chemistry, vol. 273, pp. 15621, 1998.

[3] T. Segura, Thesis Dissertation, 2004.

[4] Patrick Lim Soo, L. L., Dusica Maysinger,Adi Eisenberg, "Incorporation and Release of Hydrophobic Probes in Biocompatible Polycaprolactone-block-poly(ethylene oxide) Micelles: Implications for Drug Delivery," Langmuir, vol. 18, pp. 9996-10004, 2002.

[5] Peter Photos, B. M. D. , L.Bacakova, Frank S. Bates,Dennis E. Discher, "Polymersomes in vivo: increased stealth with both PEG density and molecular weight," Journal of Controlled Release, vol. 90, pp. 323-334, 2003.

[6] Younghoon Kim, P. D., David Christian,Dennis E. Discher, "Polymeric worm micelles as nano-carriers for drug delivery," Nanotechnology, vol. 16, pp. S484-S491, 2005.

[7] Laibin Luo, J. T., Dusica Maysinger, Adi Eisenberg, "Cellular Internalization of Poly(ethylene oxide)-b-poly(-caprolactone) Diblock Copolymer Micelles," Bioconjugate Chem, vol. 13, pp. 1259, 2002.

[8] Fariyal Ahmed, R. I. P., Goundla Srinivas, Aaron Brannan, Frank Bates, Michael L. Klein, Tamara Minko,Dennis E. Discher, "Shrinkage of a Rapidly Growing Tumor by Drug-Loaded Polymersomes: $\mathrm{pH}$-Triggered Release through Copolymer Degradation," Molecular Pharmaceutics, 2006.

[9] Annemieke Aartsma-Rus, A. A. M. J., Wendy E. Kaman, Mattie Bremmer-Bout, and J. T. d. D. Gert-Jan B. van Ommen, Judith C. T. van Deutekom, "Antisense-Induced Multiexon Skipping for Duchenne Muscular Dystrophy Makes More Sense," Am. J. Hum. Genet., vol. 74 pp. 83-92, 2004.

[10] C. R. Dass, "Vehicles for oligonucleotide delivery to tumours," Journal of Pharmacy and Pharmacology, vol. 54, pp. 3-27, 2002.
[11] Christopher J.Mann, K. H. , A.J.Cheng, T.LY,F.LLOYD,S.D.Wilton, "Antisense-induced exon skipping and synthesis of dystrophin in the mdx mice," Proc.Natl.Acad.Sci. U.S.A., vol. 98, pp. 42-27, 2001.

[12] K.E. Wells, S. F., C.J. Mann, S.D. Wilton,D.J. Wells, "Enhanced in vivo delivery of antisense oligonucleotides to restore dystrophin expression in adult mdx mouse muscle," FEBS, vol. 552, pp. 145, 2003.

[13] Radoslav Savi, L. L., Adi Eisenberg, Dusica Maysinger, "Micellar Nanocontainers Distribute to Defined Cytoplasmic Organelles," Science, vol. 300, pp. 615, 2003.

[14] Fariyal Ahmed, D. E. Discher, "Controlled release from polymersome vesicles blended with PEO-PLA or related hydrolysable copolymer," Journal of Controlled Release, vol. 96, pp. 37-53, 2004.

[15] J.C-M. Lee, H. B., B.M. Discher, M.A. Sheehan, Y.-Y. Won, F.S Bates,D.E. Discher, "Preparation, stability, and in vitro performance of vesicles made with diblock copolymers," Biotechnology and Bioengineering, vol. 73, pp. 135-145, 2001.

[16] T. Ivanova, Panaiotov, I., Boury, F., Proust, J. E., Benoit, J. P.,Verger, $\mathrm{R}$, "Hydrolysis kinetics of poly(D,L-lactide)monolayers spread on basic or acidic subphases," Colloids and Surfaces B: Biointerfaces, vol. 8, pp. 217-225, 1997.

[17] A. Belbella, Vauthier, C., Fessi, H., Devissaguet, J.-P.,Puisieux, F, "In vitro degradation of nanospheres from poly (D,L-lactides) of different molecular weights and polydispersities," International Journal of Pharmaceutics, vol. 129, pp. 95-102, 1996. 